\title{
Caring for (Big) Data: An Introduction to Research Methodologies and Ethical Challenges in Digital Migration Studies
}

\author{
Marie Sandberg and Luca Rossi
}

\section{Introduction-The Scope of This Book}

Migration, historically, is a technologically supported process. However, the current migration influx into Europe is characterised by an elaborate use of digital technological applications. Nation-states and the EU border regime apply smart technologies to control and privilege the movements of some, while restricting and criminalising the movements of others (Hess and Kasparek 2017). On the other hand, irregularised migrants and networks of solidarity use Internet and Communication Technology

\footnotetext{
M. Sandberg $(\bowtie)$

Centre for Advanced Migration Studies (AMIS), SAXO Institute, University of Copenhagen, Copenhagen, Denmark

e-mail: sandberg@hum.ku.dk

L. Rossi

Digital Design, IT University of Copenhagen, Copenhagen, Denmark e-mail: lucr@itu.dk
}

(C) The Author(s) 2022

M. Sandberg et al. (eds.), Research Methodologies and Ethical Challenges in Digital Migration Studies, Approaches to Social Inequality and Difference, https://doi.org/10.1007/978-3-030-81226-3_1 
(ICT) to facilitate passageways, thereby subtly reconfiguring how the digital platforms themselves function (Darling and Bauder 2019; Galis et al. 2016; Gillespie et al. 2016). Smartphones, for example, alleviate information precarity by providing access to networks of care as well as to in/formal work, while their meaning and uses vary depending on class, education, gender, and age (Walker et al. 2014; Wall et al. 2015, see also Vammen et al. 2021, 58). Digital technologies reshape not only every phase of the migration process itself-by providing new ways to access, share, and preserve relevant information-but also the activities of other actors, from solidarity networks to border control agencies. In doing so, digital technologies create a whole new set of challenges for migration studies: from data access to research ethics and privacy protection. When vulnerable and politicised groups like irregularised migrants constitute the primary research group, they face the risk of being (unintentionally) exploited and of unforeseen consequences based on their research participation (Pittaway et al. 2010). If issues of security, trust, and informed consent are already significant when researching migration (Zapata-Barrero and Yalaz 2020; Gillespie et al. 2016; Mackenzie et al. 2007), digital migration research only highlights those ethical challenges, adding further issues of privacy, (online) security, confidentiality, autonomy, and informed consent.

Regardless of the centrality played by technology in irregularised migrant trajectories and journeys, there is surprisingly little research that reflects on these new ethical and methodological challenges from a multidisciplinary perspective. Drawing on an interdisciplinary group of scholars that spans across critical border and migration studies, social media studies, anthropology of migration, and science and technology studies, this book offers an in-depth analysis of the most crucial methodological and ethical challenges in digital migration studies and reflects on ways to move this field forward. When digital technology becomes a lens and tool for shared decision-making and navigation among migrants, and at the same time an entrance for state authorities' surveillance and control, an update of our methodological approaches along with careful ethical considerations is urgently required.

This book therefore addresses methodological implications and ethical challenges when researching migrants' digital practices in the configuration of migration and borders. In this introductory chapter, and throughout the book, we use the term irregularised migrant. ${ }^{1}$ While we apply the term migrant in a general and not juridical sense, we choose the 
adjective irregularised to stress the inability of migrants to travel through established and safe means and describe how they find themselves navigating through illegalised and often highly dangerous ways to safety; only too often with deadly consequences.

The computational turn within social science and digital humanities has proliferated new data formats and not least new questions for research (Boellstorff and Maurer 2015; Blok and Pedersen 2014). Whereas the so-called "big data" refer to data accessed on the basis of computational social science methods through API or data scrapings from social media platforms such as Facebook and Twitter, ethnographic materials are generated on the basis of qualitative research methods and ethnographic fieldwork, including in-situ engagements like participating observations, face-to-face conversations, in-depth semi-structured interviews, and online "netnography" (Kozinets 2019). Yet, as discussed in this book, how can differences between apparently disparate data formats be conceptualised and how do we remain sensitive towards the fact that the computational tools and digital platforms themselves guide options for asking questions about the material collected? How can "big social data" and qualitative and/or ethnographic materials be brought into closer dialogue and which ethical implications should be considered? How can we aim for more in-depth analysis of migrants' digital traces, in ethically sound ways, when access to context knowledge is limited, if not absent? Perhaps the great divide between quantifiable data sets and qualitative insights requires rethinking. As suggested by Munk (2019), digital traces are at one and the same time quantitative and qualitative, since traces such as likes and shares, can be counted, while they also contain rich text, such as comments and profile data.

Whereas digital methods have grown into an established field that cross-fertilises media studies, STS, computer science, and information design (Rogers 2013, see Munk in this book), the intersections between migration and border studies and computational methods and digital ethnography are less developed. For migration and border studies, it is therefore of particular interest to discuss the challenges in drawing on digital data, which comprise computational big data on the one hand and ethnographic materials on the other. Crafting, relying on, and combining these data and material types in new ways make questions regarding data access, data interpretation, privacy protection, and research ethics generally even more pertinent. For instance, how can informed consent be ensured in online digital fora or social media platforms, and 
if not, how should ethical research be conducted? What relations of reciprocity are possible and feasible when working on virtual, and often very interchangeable, temporary digital platforms? How can we ensure and promote migrants' capacity for autonomy when pursuing digital migration research? The pertinence of these questions appears to be even stronger since the online presence of research participants is only brief and meant to be untraceable and unidentifiable.

This book discusses digital migration research methodology and ethics when conducting and combining qualitative and ethnographic fieldwork accompanied by digital data analysis. Central aspects concern both the generating of data (e.g. multiple platforms, different API, data accessibility) as well as data analysis (inconsistent data, missing data, contextdependent data). Of specific concern are the aspects of digital migration researchers accessing digital platforms used by migrants, who are subject to precarious and insecure life circumstances, lack recognised papers, and are in danger of being rejected and deported. How does the digital migration researcher ensure that the scrutinisation of online activity does not jeopardise migrants' lives and safety?

Crucially, the methodological considerations concern an ongoing discussion and reflection on the kind of knowledge digital migration researchers produce, and how to avoid compromising research participants' safety before, during, and after research is conducted. Engaging in ethically sound relationships between researchers and migrant research participants through the principles of integrity, respect, autonomy, and justice have long since been the ethos in the context of migration research (Hynes 2003; Voutira and Doná 2007). Further calls for moving beyond minimal standards of "doing no harm" to research participants in vulnerable positions have been made in order to establish more viable relationships, including reciprocal benefits to participating migrants or migrant communities (Mackenzie et al. 2007). Yet, for digital migration studies, the question remains how we can preserve and strengthen similar types of careful ethical and methodological approaches when dealing with migrants' digital data.

In this book we argue that working with digital technologies and largescale data sets in relation to ethnographic studies of digital migration practices and trajectories requires new modes of caring for (big) data. Besides the already mentioned issues of taking proper care of research participants' privacy, autonomy, and security, this also spans carefully 
establishing analytically sustainable environments for the respective data sets (see also Sandberg, Mollerup and Rossi in this book).

As a notion underpinning the contributions in this book, we propose the notion of care in the context of ethical and methodological considerations for digital migration studies, through inspiration from the work of empirical philosopher and ANT researcher Annemarie Mol. She coins the notion "the logic of care" (Mol 2008) to highlight care work as an inclusive and open-ended process integral to daily life involving a range of heterogeneous actors and relations (see also Mol et al. 2010). Even though Mol's notion of care is developed in another context and its aim differs to that of this book, as Mol presents a critique of the neoliberalised Dutch health-care system, we find her thoughts inspiring for our purpose of furthering our discussion of ethical issues in digital migration research.

Mol encourages researchers to engage in the problem of care from the beginning of any research engagement, which can likewise help to identify the questions migration and border scholars need to ask when dealing with ethical and methodological research implications. Importantly, following Mol's concept of care, care work does not rely solely on individuals but is rather distributed as a matter of concern for a set of heterogeneous and sociomaterial actors cooperating in specific situational settings. In order to de-individualise issues of ethics and methodological practices by reaching out not only to the single researcher, but also to influence the ethos of the research collective, we suggest turning our attention to the logic of care. We thus take Mol's call to pursue and nurture the logic of care as a point of departure for highlighting and nurturing the care work as a prism for how this book's contributors deal with digital data in migration research.

With the notion of (better) caring research as a point of departure, the book presents reflections on research design and methods that move beyond state-of-the-art methodologies for discussing how to combine or merge quantitative and qualitative methods with the prospect of transgressing boundaries between online and offline data. Ultimately, this will facilitate more viable research on the complex, cross-platform nature of migrants' information and communication technology (ICT) use.

In this introduction, we will first recapture some main characteristics of ethical and methodological considerations within migration studies and discuss how this field has sought to move beyond the "do no harm" approach (Stierl 2020). We will then present the emerging field of digital migration research in order to pinpoint the specificities of the ethical 
and methodological considerations required within this field of research. Rather than starting from ground zero, we propose to learn from and nurture the already established research ethics developed within migration studies and related fields.

Second, we turn our attention to the issue of big data and how to care for those data in ethically viable ways. Here we discuss the remaining question concerning how we can preserve the same type of careful approach when dealing with digital data as when conducting ethnographic and qualitative research with vulnerable groups such as migrants and people living in the context of insecure and violent circumstances.

Third, we outline the chapters of this book and how they contribute new avenues and ways for furthering the ethical dimension of digital migration research. In conclusion, we highlight how these chapters, rather than proposing any quick fixes or set solutions, offer alternative viewpoints and stimulate critical thinking on the part of border authorities engaging with migrants' digital practices, as well as migration researchers, in order to strengthen and promote ethically rigorous research.

\section{ETHICAL AND METHODOLOGY Challenges in Migration Studies}

Migration studies as a field characterised by its interdisciplinarity has a long track record of using a multiplicity of research methodologies and approaches. This quest for multiplicity is based on the maxim that complex phenomena, such as migrational issues, call for insights, perspectives, and contributions from several disciplines. Because of the moving field and wide geographical distribution of migration studies, research questions can be difficult to answer with a singular method. However, as argued by Voutira and Doná $(2007,166)$, some certain characteristics still unite research on refugees and migration as a field of study, namely, a genuine interest in pursuing bottom-up perspectives to further migrants' points of view, along with a blurred line distinguishing between advocacy and scholarship (ibid., 167). Likewise, more state-centred perspectives (e.g., in international relations, law, and economics) in migration studies tend to include critical perspectives on migration policy and border regimes (ibid.).

A further joint characteristic can be added to the field of migration studies, namely, a distinct preoccupation with research ethics engaging the principles of integrity, respect, autonomy, and justice (Hynes 2003; 
Voutira and Doná 2007; Zapata-Barrero and Yalaz 2020). Witnessing one's research (unintentionally) harming the subject of research, the community of the research subject in question, or being used politically to further certain agendas, is undoubtedly the worst-case scenario for any migration scholar. However, as argued by Mackenzie et al. (2007), migration research has since long been in dire need of moving beyond minimal standards of "doing no harm" when researching participants in vulnerable positions and subsequently establishing more viable relationships between researchers and research participants, including the enabling of reciprocal benefits to participating migrants or migrant communities (Mackenzie et al. 2007, 300, see also Stierl 2020). Mackenzie et al. highlight the need for recognising and promoting migrants' agency and autonomy in terms of capabilities and rights (ibid., 302), a call also reflected in several chapters of this book, which draw on inspiration from the Autonomy of Migration (AoM) approach.

In digital migration studies, as we argue, the question remains how we can preserve the same kind of careful ethical and methodological approaches when dealing with migrants' digital practices and digital data. In the following, we discuss how to move this mode of caring for our research participants in migration research ethics into the context of digital data.

\section{Digital Migration Research-Past and Future Methodological Challenges in an Emerging Field}

While still relatively young, digital migration research is quickly consolidating into a fully fledged academic field. It already satisfies most of the criteria that we usually adopt when defining an academic field of research: dedicated special issues (Leurs and Smets 2018, 1), international conferences (e.g., connectingeuropeproject.eu), as well as a certain level of internal reflection (Leurs and Prabhakar 2018; Andersson 2019, and many chapters in this book). In their introduction to the special issue for the international journal Social Media + Society, Leurs and Smets (2018, 1-16) focussed on the context surrounding the emerging field by asking a set of questions including the following, which we find extremely relevant for our purpose: Where are the field and focus of digital migration studies? And where is the human in digital migration? Discussing these questions seems particularly relevant for understanding how a careful ethical and 
methodological approach has emerged and can be further developed in digital migration research.

Migrants were using media technologies, such as letters from friends who had already migrated; news and video content from "across the border" (Mai 2001, 95) first; and digital media later, long before digital migration studies acknowledged that digital traces were a viable data source. Although Appadurai stressed the connection between global migration and digital technologies already in 1996, it took twenty years for digital migration studies to attract global attention as a necessary and timely approach for understanding contemporary migration. What happened during those twenty years is of interest when understanding the promises and the expectations that accompanied the early days of digital migration studies. For the first decade of the twenty-first century, digital data were already used to study online communities, which offered researchers unprecedented access to diasporic communities around the world (Komito and Bates 2009, 232). From this perspective, the combination of digital data and migration studies emerged within the context defined by digital ethnography (Hine 2008; Markham 2005) where online communities (of migrants) and their (digital) practices were the object of research. Later, the focus on what was deemed to be possible to study with digital data changed. The combined effect of social media and digital traces (Giglietto et al. 2012, 145; Venturini and Latour 2010) as well as growing social awareness of the use of large amounts of digital data to analyse social phenomena (Kitchin 2014) created the perfect background for a paradigm shift. Instead of studying specific communities that researchers had to access through ethnographic principles, the digital traces that migrants were leaving behind in the form of GPS coordinates, social media posts, likes, or shares, contributed to the idea that it was possible to study migrations through "data only" without the need to engage with the producers of those data: the migrants. This built on the parallel emergence of data from social media platforms and it was considered a comprehensive - and sometimes preferable-research option for social scientists and digital researchers alike (ibid., 1; Felt 2016, 1). Despite several attempts to call for a critical reflection on the epistemological consequences of this data revolution (Kitchin 2014, 1) and the emergence of several empirical limitations (Tufekci 2014, 505), the new perception of data reached migration research in combination with the historical events that once more afforded migrations, asylum seekers, and migration-related policies centre stage in global discussions. The 
so-called "European refugee crisis", which continued for most of the second decade of the century, provided the "perfect" societal context for larger-than-ever use of digital data in migration studies and for the parallel datafication of migrations (Leurs and Smets 2018, 4). Migrants and asylum seekers became represented by their digital data in a variety of different communication artefacts, policy reports, and academic research, and the ways in which this happened, including the narratives underlying this process, are far from inconsequential.

This process of an accelerated craving for big, digital migration data was facilitated by the strong anchoring of digital migration studies in the field of (digital) media and communication research. Several of the main theoretical and methodological approaches are either native to the fields of media studies or have been used in the context of media studies for decades (see, for example, Canidatu et al. 2019, 36). The perceived social relevance connected with the "European refugee crisis" in Europe, the societal predisposition towards the ongoing data revolution, and the availability of a set of research methods and practices from compatible academic fields, made the first 15 years of digital migration research an addition to the existing field of migration studies rather than an extension of it. As Yalaz and Zapata-Barrero $(2018,14)$ point out in their work covering 15 years of qualitative migration studies, between 2000 and 2016, the overall number of articles published in migration studies doubled, though this increase was not produced by an explosion in the qualitative approach to migration studies, which remained a stable quota over the years. The explosion was due to the growing production of quantitative and digital methods and approaches to migration studies that gained new relevance during this period. Beside the enthusiasm for a new and promising set of research methods, it should be noted how something quite unique happened when digital methods reached the area of migration studies. Entire research domains that in a pre-digital methods scenario would have previously required a considerable amount of contextual knowledge and in-situ relations became available, just a few clicks away, to a much larger group of scholars.

Within this process, digital migration studies, rather than building its ethical stand and approaches by expanding the more careful approach defined by qualitative migration research, often adopted a media-centric (Smets et al. 2019) approach in which ethical concerns focused more on the data than on the subjects behind it. This does not mean in any way that existing digital migration research lacks ethics, but that it has, so far, 
not fully delivered on Mackenzie et al.'s (2007) idea of moving beyond the minimal ethical standard. How is it possible for research based on the digital traces left by migrants to enable reciprocal benefits for migrants or migrant communities? (Ibid., 300). How do we recognise autonomy and agency when the migration process is, partially or entirely, datafied? How do we care for all the data that allows us to research migrations? While there are no easy answers to these questions, we think that many of the chapters in this collection show that these are very pertinent questions. As we argue, rethinking the way in which data is understood in digital migration studies in more careful ways can result in a stronger connection between issues and theoretical apparatus.

\section{It Is Big Data-Who Cares?}

Following the ideological enthusiasm for the ongoing data revolution, data has emerged as the technological solution for any type of border control (Bigo 2014, 209-225; Broeders 2007, 71-92). Today more than ever, human mobility is represented, studied, and governed through big data. Large data sets of biometric data promise to protect the (smart) borders by combining efficiency with safety (Sontowski 2018, 27302746) and when data is not available, ad-hoc initiatives are launched to fill the gaps. ${ }^{2}$ It is fair to say that governments' and other international actors' interest in migrants' digital data has never been greater, and this is especially true of data that is perceived to be useful for policing smart borders (ibid.) or preventing allegedly illegal immigration (Latonero and Kift 2018).

Within this scenario, it should be clear that the unintended and unforeseen consequences of migrants' digital data collected for research purposes can be nefarious, and that the legal privacy-oriented procedures in place in many research institutions (e.g., GDPR compliance) might not even achieve an adequate state of "doing no harm". For these reasons, we see that more care is required regarding how we approach digital migration data for research. We see the logic of care being adopted in research projects as a continuous open-ended process (Mol, 2008) that could be summarised in two interrelated steps: firstly, before the data collection, and secondly, during and beyond the active time of research. As a first step, approaching migrants' digital data "with care" means pursuing a more critical approach to the use of big data in migration research where the data is not an unquestionable proxy for social activity. From this perspective, the relations between the social practices behind the 
data production are fully understood, and their links with the issue of migration research are clearly conceptualised to avoid unnecessary and potentially harmful data collection. This form of care builds on the idea of curation that Munk suggests $(2019,164)$ as a way of bridging the quali-quantitative divide. Munk defines curation as "Critically reappropriating (and thus manually curating) onlife traces to speak on behalf of certain phenomena or address certain questions" (ibid.). Caring for big data used in migration research points in a similar direction. While it is certainly possible to imagine a non-manual form of curation, the key element is the re-appropriation of the digital traces within the theoretical design of the research and making methodological decisions on that basis.

The second step of a careful approach to migrants' digital data is to create an analytically viable and sustainable environment for the research data. Research practices rooted in digital methods are often expected to share the data sets that have been used for the research efforts. Replicability of the research results as well as the possibility for further research are common arguments used to support this request (Weller and KinderKurlanda 2016, 166). While the practice of data sharing is well established in the context of clinical data (Bull et al. 2015, 225-238) and some practices have been adopted for sharing social media data (Benton et al. 2017, 94-102), there seems to be very little guidance when it comes to migrants' digital traces. Data sharing, as well as post-research data storage, needs to be balanced against the interests of all the actors involved, bearing in mind that data value and potential harm caused by data are not stable over time. This needs to balance apparently conflicting aspects: on the one side, as Weller and Kinder-Kurlanda note (2016, 170), the reproducibility value of digital traces deteriorates over time while, on the other side, the risk of personal harm exists even when a considerable period of time has passed, as a growing body of legal instruments have acknowledged (e.g., in the-still limited-implementation of the so-called "right to be forgotten" specified in Article 17 of GDPR).

Digital migration studies have huge potential to provide insights into some of the most relevant issues of our time. Nevertheless, the very same characteristics that make the approach powerful and have contributed to its rapid growth as an academic research field can easily represent a risk for the subjects involved. This calls for a more critical, reflective, in other words more careful, approach to big data in the context of migration studies. 


\section{OUTLINE OF THE BOOK}

The chapters in this book reflect an interdisciplinary theoretical framework that draws on methodologies from critical border and migration studies (cf. Casas-Cortés et al. 2015), social media studies (cf. Rodríguez et al. 2014; Croeser 2014), anthropology (cf. Ingold 2018; Strathern 1991/2004), and science and technology studies (STS) (cf. Dijstelbloem and Meijer 2011). The methods used include policy analysis, qualitative approaches entailing non-participant observation, ethnographic interviews, and media device tours as well as data-scraping techniques for analysing social media data. This multiplicity of research methods is a deliberate editorial choice, as we believe that analysing the dynamics and consequences of borders, mobilities, and technologies requires a multi-faceted methodological toolbox.

A theoretical premise of the book's research insights is that borders are not fixed geographical entities but a set of complex practices in a constant state of becoming, and that technology transforms not only migration but also forms of solidarity with migrants. The analyses presented in this volume therefore not only include migrants' use of ICT, but also solidarity networks and groups facilitating refugee reception. This, in turn, requires careful ethical considerations when working with data gained from migrants' stories as well as digital imprints from solidarity networks facilitating irregularised border crossings.

The idea for the current book was developed as part of the interdisciplinary research initiative called "DIGINAUTS: Migrants' digital practices in/of the European border regime" that began in 2018, funded by the Velux Foundation Denmark. The DIGINAUTS project argues that migrants' uses of technology not only challenges our usual ways of thinking about migration but also subtly reconfigures the functioning of these technologies themselves.

The methodological implications of working with digital data in migration studies and thus ideas relating to the further focus of this book were extensively discussed during a methods workshop at the IMISCOE conference in Malmö in June 2019 as well as a workshop that took place in Copenhagen in October 2019, hosted by the Ethos lab at the IT University Copenhagen, both organised by the DIGINAUTS project. During these activities, it was clear that a growing number of migration researchers are aware of the possibilities offered by digital data but are 
facing methodological and ethical challenges. We have invited contributions from researchers with whom we have worked closely during the book project as well as researchers working with topics highly relevant for this book. Together, these contributions represent state-of-the art within critical migration studies as well as digital migration studies and social media studies.

This introductory chapter is followed by two parts, each with a set of chapters. Part I highlights "Digital and Qualitative Data Dynamics" whereas Part II scrutinises in detail "Ethical Challenges in Digital Migration Research and Beyond". The book concludes with a third "Comments" part, in which three researchers, each with distinguished research expertise in their respective fields of migration studies and digital research, offer concluding reflections and comments spanning the contributions in this book.

The first part "Digital and Qualitative Data Dynamics" contains four chapters that present the many facets of digital data in the context of dealing with migration. The part contains specific proposals to conduct research with migrants' digital data, both directly and through derivative products, as well as overviews describing the field of digital migration studies in its complexity. In Chapter 2, "Migrant Digital Space: Building an Incomplete Map to Navigate Public Online Migration", the authors Vasiliki Makrygianni, Ahmad Kamal, Luca Rossi, and Vasilis Galis discuss the challenges encountered while sampling online data from a largely unknown population and especially so from "minor actors" such as the digital spaces set up by migrants. They reflect on these challenges by introducing the concept of Migrant Digital Space as an online (and offline) arena where information, knowledge, communication, advocacy, and representation of migrants are enacted by leveraging contemporary digital technologies. From this perspective, migrant digital space is inherently unstable, and its definition is an integral part of any research on migrants' digital practices.

In Chapter 3, "Contrapuntal Connectedness: Analysing Relations Between Social Media Data and Ethnography in Digital Migration Studies”, Marie Sandberg, Nina Grønlykke Mollerup, and Luca Rossi explore the potentials of combining ethnography and "big" social media data in analysing fieldwork carried out with Syrian refugees and solidarians in the Danish-Swedish borderlands 2018-2019, as well as data collected during 2011-2018 from 200 public Facebook pages run by solidarity organisations, NGOs, and informal refugee welcome and solidarity networks. The authors suggest that the relationship between the 
types of research material can be conceived as contrapuntal, which means that the material types are recognised as different but fundamentally interconnected. Inspired by Tim Ingold (2018), lines of counterpoint (known from musical theory when different musical lines are played simultaneously, while being at once independent and related) are translated into human movements, which carry on alongside one another, not as a summation of parts but as the correspondence of its particulars. This contrapuntal connectedness is explored and further qualified with the aim of identifying potentials and further questions for digital migration research.

Chapter 4, "Migration Trail: Exploring the Interplay Between Data Visualisation, Cartography and Fiction" by Giacomo Toffano and Kevin Smets, departs from a case study on Migration Trail, an online interactive platform, and discusses the potential in techniques that visualise migration. Data visualisations, in this perspective, present migration scholars with a new set of problems and ethical challenges. What narratives of migration emerge from the way data are visualised, and who bears responsibility for those narratives? The authors apply a mixed-method approach that includes both multimodal and discourse analysis to understand and scrutinise the interaction of textual, audio, visual, and spatial elements of communication in Migration Trail.

The final chapter in this part, Chapter 5, "Migration Multiple? Big Data, Knowledge Practices and the Governability of Migration" by Laura Stielike, explores the production of knowledge on migration at the interface between migration research built on big data and governance. Applying discourse analysis to research papers based on big data, the chapter carves out characteristic features of such migration studies. In her work, Stielike highlights the risk of big-data-based migration research connecting with pre-existing narratives about migration that present it as an object of government.

The second part of the book "Ethical Challenges in Digital Migration Research and Beyond" contains three chapters that all zoom in on the ethical challenges faced during digital migration research. Chapter 6, "Impossible Research? Ethical Challenges in the (Digital) Study of Deportable Populations Within the European Border Regime", continues along similar lines. The authors, Leandros Fischer and Martin Bak Jørgensen, discuss and reflect on the ethical challenges faced when conducting ethnographic research and online ethnography among groups facing deportation. They consider the implications of doing or not doing 
such research and discuss whether this is "impossible research", due to national authorities being provided with access to data that migrants would prefer remained less visible. Migration researchers, the authors argue, should adhere to ethical principles of working with vulnerable groups such as migrants scheduled for deportation, without compromising their sense of agency. Taking its cue from a "militant research approach" along with the "autonomy of migration" (AoM) perspective, the chapter argues for reflexive and contextualised ethics that aim to promote solidarity and social change.

Chapter 7, "The Redundant Researcher: Fieldwork, Solidarity and Migration" by Vasilis Galis, does not offer solutions to this ethical challenge but reveals a set of critical, productive self-reflections on the author's own research practices. On the basis of fieldwork conducted on the islands of Lesvos and Chios during the winter of 2019, the chapter asks: What is it like to conduct academic research on a phenomenon that is polluted by vested political interests, personal strategies, ideological loyalties, propaganda, and hazards? Why is this fieldwork relevant and for whom? In order to answer these questions, the chapter proposes four principles for an emancipatory migration research paradigm to ensure that the research conducted promotes migrants' agency, addresses concerns relevant to migrants themselves, supports migrant struggles, and ensures the safety and integrity of migrants. Whereas the two preceding chapters discuss, in different ways, how to "do no harm" or how to use research to stipulate and empower migrant struggles, Chapter 8, "Emotional Introspection: The Politics and Challenges of Contemporary Migration Research" by Ninna Nyberg Sørensen, discusses an often-overlooked question: How to do no harm to ourselves, as researchers, when doing migration research in demanding and stressful situations often embedded in ethically challenging contexts? Based on long-term observations and experience within the field, combined with a set of recently conducted interviews with migration researchers, Sørensen discusses the institutional cultures and structures in migration research in the context of stricter migration policy and practice. Sørensen argues that we need to attend to the emotional aspects of conducting fieldwork in complex, increasingly more insecure and challenging situations. Along with making the emotional implications more explicit, emotional introspection is therefore called for, before, during, and after research.

The concluding three shorter commentaries address both of the main issues of this book: Big data-research methodologies and ethical 
challenges in digital migration studies as well as reflecting on the contributions of this book. Koen Leurs, an expert in digital migration studies, reflects in his comment "On Data and Care in a Migration Context"; Anders Kristian Munk, who is very well versed in the digital humanities and mapping of this controversial field, argues that we should consider "Caring as Critical Proximity: A Call for Toolmaking Digital Migration Studies"; and Anna Lundberg, a migration research scholar with a keen interest in welfare law and academic activism, asks: "What Should We Do as Intellectual Activists? A Comment on the Ethico-political in Knowledge Production".

\section{CONCLUSION}

In conclusion, this book provides a unique contribution to the emerging field of digital migration research by bridging insights from critical migration and border research, anthropology of migration, feminist theory, science and technology studies (STS) with social media and communications research within digital humanities. These research approaches have in common that the exceptionality and irregularity of categories such as "refugee" and "migrant" are critically and self-reflexively assessed. The authors thus argue that it is essential to carefully reflect on researchers' own positioning as being part of the research challenges they seek to address. By devoting special attention to the links between digital research methodologies and ethics in migration studies, the chapters cover innovative approaches that intersect digital social media studies, critical border and migration studies, and ethnography, and aim to contribute to ongoing and emerging debates on research ethics in digital migration research and the complex entanglements of migration with technology. The following chapters should stimulate a much-needed critical reflection on ethical and methodological issues in digital migration research. As we have argued, researching migrants' digital practices in the configuration of migration and borders calls for new modes of caring for (big) data. Besides taking proper care of research participants' privacy, autonomy, and security, this also spans carefully establishing analytically sustainable environments for the respective data sets, as outlined here. Finally, we aspire this book to be used by an interdisciplinary readership consisting of migration scholars and students alike, and that by stimulating further methodological discussion in our fields, it will enable collective reflection related to the ethics of digital migration. 


\section{Notes}

1. For a discussion regarding the term "refugee" as a "categorical anomaly", see Voutira and Doná $(2007,163)$.

2. Very interesting examples of this are the "Filling data gaps" initiatives launched by the UNHCR joint data center on Forced Displacement: https://www.jointdatacenter.org/what-we-do/\#filling-data-gaps.

\section{BIBLIOGRAPHY}

Andersson, Kerstin B. 2019. "Digital Diasporas: An Overview of the Research Areas of Migration and New Media through Narrative Literature Review." Human Technology 15 (2): 142-180.

Appadurai, Arjun. 1999. "Globalization and the Research Imagination." International Social Science Journal 51 (160): 229-238.

Benton, Adrian, Glen Coppersmith, and Mark Dredze. 2017. "Ethical research protocols for social media health research." In Proceedings of the First ACL Workshop on Ethics in Natural Language Processing, pp. 94-102.

Bigo, Didier. 2014. "The (In) Securitization Practices of the Three Universes of EU Border Control: Military/Navy-Border Guards/Police-Database Analysts." Security Dialogue 45 (3): 209-225.

Blok, Anders, and Morten Axel Pedersen. 2014. "Complementary Social Science? Quali-Quantitative Experiments in a Big Data World." Big Data \& Society 1 (2): 2053951714543908.

Boellstorff, Tom, and Bill Maurer. 2015. "Introduction." In Data, Now Bigger and Better!, edited by Boellstorff Tom and Maurer Bill. Chicago: Prickly Paradigm Press.

Broeders, Dennis. 2007. "The New Digital Borders of Europe: EU Databases and the Surveillance of Irregular Migrants." International Sociology 22 (1): 71-92.

Bull, Susan, Nia Roberts, and Michael Parker. 2015. "Views of ethical best practices in sharing individual-level data from medical and public health research: A systematic scoping review." Journal of Empirical Research on Human Research Ethics 10 (3): 225-238.

Candidatu, Laura, Koen Leurs, and Sandra Ponzanesi. 2019. "Digital Diasporas: Beyond the Buzzword: Toward a Relational Understanding of Mobility and Connectivity." The Handbook of Diasporas, Media, and Culture, 31-47. Hoboken: Wiley.

Casas-Cortes, Maribel, Sebastian Cobarrubias, Nicholas De Genova, Lenda Garelli, Giorgio Grappi, Charles Heller, sabine Hess, Bernd Kasparek, Sandro Mezzadra, Brett Neilson, Irene Peano, Lorenzo Pezzani, John Pickles, Federico Rahola, Lisa Riedner, Stephan Scheel and Martina Tazzioli. 2015. 
“New Keywords: Migration and Borders." Cultural Studies 29 (1): 55-87. https://doi.org/10.1080/09502386.2014.891630.

Croeser, Sky. 2014. “Changing Facebook's Architecture." An Education in Facebook, 185-195.

Darling, Jonathan, and Harald Bauder, eds. 2019. Sanctuary Cities and Urban Struggles: Rescaling Migration, Citizenship, and Rights. Manchester University Press.

Dijstelbloem, Huub, and Albert Jacob Meijer, eds. 2011. Migration and the New Technological Borders of Europe. London: Palgrave Macmillan.

Ehn, Billy, Orvar Löfgren, and Richard Wilk. 2015. Exploring Everyday Life: Strategies for Ethnography and Cultural Analysis. Lanham: Rowman \& Littlefield.

Felt, Mylynn. 2016. "Social Media and the Social Sciences: How Researchers Employ Big Data Analytics.” Big Data \& Society 3 (1): 2053951716645828.

Galis, Vasilis, Spyros Tzokas, and Aristotle Tympas. 2016. "Bodies Folded in Migrant Crypts: Dis/Ability and the Material Culture of Border-Crossing." Societies $6(2)$ : 10.

Giglietto, Fabio, Luca Rossi, and Davide Bennato. 2012. “The Open Laboratory: Limits and Possibilities of Using Facebook, Twitter, and YouTube as a Research Data Source." Journal of Technology in Human Services 30 (3-4): 145-159.

Gillespie, Marie, Lawrence Ampofo, Margaret Cheesman, Becky Faith, Evgenia Iliadou, Ali Issa, Souad Osseiran, and Dimitris Skleparis. 2016. "Mapping Refugee Media Journeys." Smartphones and Social Media Networks. Research report. The Open University. http://www.open.ac.uk/ccig/sites/www.open. ac.uk.ccig/files/Mapping\%20Refugee\%20Media\%20Journeys\%2016\%20May\% 20FIN\%20MG_0.pdf.

Hess, Sabine, and Bernd Kasparek. 2017. "Under Control? Or Border (as) Conflict: Reflections on the European Border Regime". In Perspectives on the European Border Regime: Mobilization, Contestation, and the Role of Civil Society, edited by Ove Sutter and Eva Yokhama. Social Inclusion 5, 58-68.

Hine, Christine. 2008. "Virtual Ethnography: Modes, Varieties, Affordances." The Sage Handbook of Online Research Methods, 257-270.

Hynes, Tricia. 2003. "New Issues in Refugee Research." The Issue of 'Trust' or 'Mistrust'in Research with Refugees: Choices, Caveats and Considerations for Researchers. Geneva: Evaluation and Policy Analysis Unit, The United Nations Refugee Agency.

Ingold, Tim. 2018. Anthropology: Why It Matters. Cambridge: Wiley.

Kitchin, Rob. 2014. "Big Data, New Epistemologies and Paradigm Shifts." Big Data \& Society 1 (1): 2053951714528481. 
Komito, Lee, and Jessica Bates. 2009. "Virtually Local: Social Media and Community among Polish Nationals in Dublin." In Aslib Proceedings. Bingley: Emerald Group Publishing Limited.

Kozinets, Robert V. 2019. Netnography: The Essential Guide to Qualitative Social Media Research. London: Sage.

Latonero, Mark, and Paula Kift. 2018. "On Digital Passages and Borders: Refugees and the New Infrastructure for Movement and Control." Social Media + Society 4 (1): 2056305118764432.

Leurs, Koen, and Kevin Smets. 2018. "Five Questions for Digital Migration Studies: Learning from Digital Connectivity and Forced Migration in (to) Europe." Social Media+ Society 4 (1): 2056305118764425.

Leurs, Koen, and Madhuri Prabhakar. 2018. "Doing Digital Migration Studies: Methodological Considerations for an Emerging Research Focus." Qualitative Research in European Migration Studies, 247-266. Basel: Springer.

Mackenzie, Catriona, Christopher McDowell, and Eileen Pittaway. 2007. "Beyond 'Do No Harm: The Challenge of Constructing Ethical Relationships in Refugee Research." Journal of Refugee Studies 20 (2): 299-319.

Mai, Nicola. 2001. "The Role of Italian Television in Albanian Migration to Italy." Media and Migration: Constructions of Mobility and Difference, edited by Russell King and Nancy Wood, 95-109. New York: Routledge.

Markham, Annette N. 2005. "The Methods, Politics, and Ethics of Representation in Online Ethnography." In The Sage Handbook of Qualitative Research. Thousand Oaks, CA: Sage.

Mol, Annemarie. 2008. The Logic of Care: Health and the Problem of Patient Choice. Abingdon: Routledge.

Mol, Annemarie, Ingunn Moser, and Jeanette Pols. 2010. "Care: Putting Practice into Theory." In Care in Practice. On Tinkering in Clinics, Homes and Farms, edited by Annemarie Mol, Ingunn Moser, and Jeanette Pols, 7-26. Bielefeld: Transcript Verlag.

Munk, Anders Kristian. 2019. "Four Styles of Quali-Quantitative Analysis: Making Sense of the New Nordic Food Movement on the Web." Nordicom Review 40 (1): 159-176.

Pittaway, Eileen, Linda Bartolomei, and Richard Hugman. 2010. “'Stop Stealing Our Stories': The Ethics of Research with Vulnerable Groups." Journal of Human Rights Practice 2 (2): 229-251.

Rodriguez, Manuel Gomez, Krishna Gummadi, and Bernhard Schoelkopf. 2014. "Quantifying Information Overload in Social Media and Its Impact on Social Contagions." In Proceedings of the International AAAI Conference on Web and Social Media, vol. 8, no. 1.

Rogers, Richard. 2013. Digital Methods. Cambridge, MA: MIT press. 
Smets, Kevin, Koen Leurs, Myria Georgiou, Saskia Witteborn, and Radhika Gajjala, eds. 2019. The Sage Handbook of Media and Migration. London: Sage.

Sontowski, Simon. 2018. "Speed, Timing and Duration: Contested Temporalities, Techno-political Controversies and the Emergence of the EU's Smart Border." Journal of Ethnic and Migration Studies 44 (16): 2730-2746.

Stierl, Maurice. 2020. "Do No Harm? The Impact of Policy on Migration Scholarship." In Environment and Planning C: Politics and Space, October 2020. https://doi.org/10.1177/2399654420965567.

Strathern, Marilyn. 1991/2004: Partial Connections. Updated edition 2004: Washington, DC: Altamira Press, Rowman \& Littlefield.

Thoreau, Henry David. 2016. "Walking." In The Making of the American Essay, edited by John D'Agata, 167-195. Minneapolis: Graywolf Press.

Tufekci, Zeynep. 2014. "Big Questions for Social Media Big DATA: Representativeness, Validity and Other Methodological Pitfalls." In Proceedings of the International AAAI Conference on Web and Social Media, vol. 8, no. 1.

Vammen, Ida M. S., Sine Plambech, Ahlam Chemlali, and Ninna Nyberg Sørensen. 2021. "Does Information Save Migrants' Lives? Knowledge and Needs of West African Migrants en Route to Europe". DIIS Report, 2021, no. 1: 1-65. Copenhagen.

Venturini, Tommaso, and Bruno Latour. 2010. "The Social Fabric: Digital Traces and Quali-quantitative Methods." In Proceedings of future en seine 87-101.

Voutira, Eftihia, and Giorgia Doná. 2007. "Introduction. Refugee Research Methodologies: Consolidation and Transformation of a Field." Journal of Refugee Studies 20 (2): 163-171.

Walker, Rea, Lee Koh, Dennis Wollersheim, and Pranee Liamputtong. 2014. "Social Connectedness and Mobile Phone Use Among Refugee Women in Australia." Health of Social Care in the Community 23 (3): 325-336.

Wall, Melissa, Madeline Otis Campbell, and Dana Janbek. 2015. "Syrian Refugees and Information Precarity." New Media \& Society, 1-15. Published online before print July 2, 2015. https://doi.org/10.1177/146144481559 1967.

Weller, Katrin, and Katharina E. Kinder-Kurlanda. 2016. “A Manifesto for Data Sharing in Social Media Research." In Proceedings of the 8th ACM Conference on Web Science, 166-172.

Yalaz, Evren, and Ricard Zapata-Barrero. 2018. "Mapping the Qualitative Migration Research in Europe: An Exploratory Analysis." In Qualitative Research in European Migration Studies, 9-31. Cham: Springer.

Zapata-Barrero, Richard, and Yalaz Evren. 2020. "Qualitative Migration Research Ethics: A Roadmap for Migration Scholars." Qualitative Research Journal 20 (3): 269-279. https://doi.org/10.1108/QRJ-02-2020-0013. 
Open Access This chapter is licensed under the terms of the Creative Commons Attribution 4.0 International License (http://creativecommons.org/licenses/ by $/ 4.0 /$ ), which permits use, sharing, adaptation, distribution and reproduction in any medium or format, as long as you give appropriate credit to the original author(s) and the source, provide a link to the Creative Commons license and indicate if changes were made.

The images or other third party material in this chapter are included in the chapter's Creative Commons license, unless indicated otherwise in a credit line to the material. If material is not included in the chapter's Creative Commons license and your intended use is not permitted by statutory regulation or exceeds the permitted use, you will need to obtain permission directly from the copyright holder.

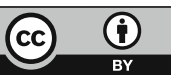

